Article

\title{
Available Energy in Cars' Exhaust System for IoT Remote Exhaust Gas Sensor and Piezoelectric Harvesting
}

\author{
Francesco Madaro ${ }^{1, *(\mathbb{D}}$, Iman Mehdipour ${ }^{1}\left(\mathbb{D}\right.$, Antonio Caricato ${ }^{2}$, Francesco Guido ${ }^{1}$, \\ Francesco Rizzi ${ }^{1}(1)$, Antonio Paolo Carlucci ${ }^{2} \mathbb{B}$ and Massimo De Vittorio ${ }^{1}$ \\ 1 Center for Biomolecular Nanotechnologies, Istituto Italiano di Tecnologia, 73010 Arnesano (LE), Italy; \\ iman.mehdipour@iit.it (I.M.); francesco.guido@iit.it (F.G.); francesco.rizzi@iit.it (F.R.); \\ massimo.devittorio@iit.it (M.D.V.) \\ 2 Dipartimento di Ingegneria dell' Innovazione, Università del Salento, 73100 Lecce, Italy; \\ antonio.caricato1@unisalento.it (A.C.); paolo.carlucci@unisalento.it (A.P.C.) \\ * Correspondence: francesco.madaro@iit.it; Tel.: +39-377-435-4866
}

Received: 29 June 2020; Accepted: 11 August 2020; Published: 12 August 2020

check for updates

\begin{abstract}
The exhaust system of the light-duty diesel engine has been evaluated as a potential environment for a mechanical energy recovery system for powering an IoT (Internet of Things) remote sensor. Temperature, pressure, gas speed, mass flow rate have been measured in order to characterize the exhaust gas. At any engine point explored, thermal energy is by far the most dominant portion of the exhaust energy, followed by the pressure energy and lastly kinetic energy is the smallest fraction of the exhaust energy. A piezoelectric flexible device has been tested as a possible candidate as an energy harvester converting the kinetic energy of the exhaust gas flow, with a promising amount of electrical energy generated in the order of microjoules for an urban or extra-urban circuit.
\end{abstract}

Keywords: light-duty diesel engine; piezoelectric harvester; IoT remote sensor; aluminum nitride

\section{Introduction}

European emissions standards [1,2] tighten limits on air pollutant emissions and require the best technology currently available for vehicle emission control. Many of these technologies require the on-board measurement of regulated pollutant emission levels in order to guarantee the maximum conversion efficiency.

On the other hand, in Europe the New European Driving Cycle (NEDC) procedure has been proven nonrepresentative of real world vehicle operation, thus leading to a gap between officially reported emissions and the ones experienced during real world operation [3]. New procedures require the measurement of pollutant emission levels during real driving emission conditions and portable emission sensing devices have been reported and proven to be reliable ways of monitoring real driving emissions [4-6].

The above considerations both lead to a pressing need for portable gas monitoring systems. The exhaust gas monitoring system is a comprehensive system made of the gas sensors, data logger, data transceiver, and power system. In order to avoid issues related to replacing batteries powering the sensors and the transceiver, several ways have been reported to recover energy from the engine [6-16]. The scope would be to design a complete IoT system for sensing, logging and transmitting data from the exhaust gas [17] and ideally, the system should be self-powered using the energy available in the environment in which it operates.

Piezoelectric transduction is a very promising mechanism to directly convert the kinetic energy of a fluid into available electrical energy and piezoelectric energy harvesting has been evaluated and 
reviewed $[18,19]$ in several applications. The vortex-induced vibration method is a common practice used to harvest the kinetic energy of a fluid using piezoelectric transducers [20].

This work reports the comprehensive evaluation of the energy available and harvestable in exhaust gas in different forms, such as thermal, pressure and kinetic, at different positions of the exhaust system, and at different engine operating conditions (engine speed and torque). Physical properties of the gas such as temperature, pressure, gas speed have been measured, in order to provide a complete description of the environment in which the harvester and the IoT smart gas sensor would operate.

The work also describes the preliminary results of the installation of a piezoelectric harvester and simultaneous measurement of several parameters of the engine in real driving conditions and measurement of the electrical energy produced.

Thoretical Model for Evaluating Exhaust Gas Energy

In a conventional internal combustion engine, approximately one-third of total fuel input energy is converted to useful work, one-third is dissipated by the cooling system, radiation and friction, and, finally, another third is expelled by the exhaust gases [21,22].

Diesel internal combustion engines' cycles have a substantial quantity of energy that is expelled from the exhaust system in the exhaust gases as described with the energy split diagram shown in Figure 1.

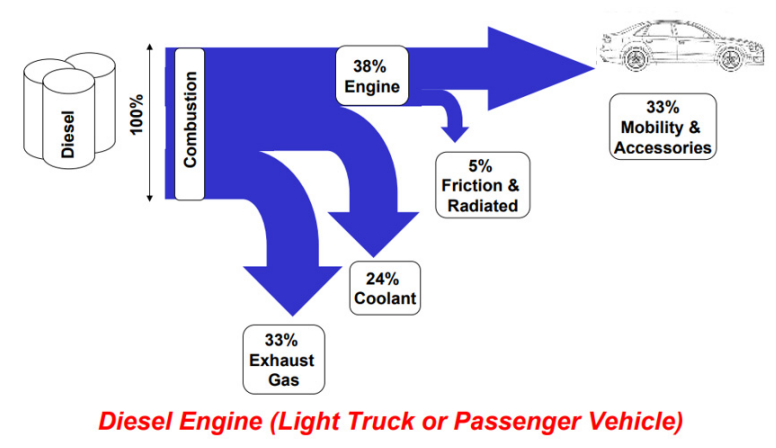

Figure 1. Energy split for a diesel engine (light truck or passenger vehicle) [23].

The energy balance is shown in Equation (1):

$$
\dot{Q}_{\text {total }}=P_{i}+\dot{Q}_{\text {coolant }}+\dot{Q}_{\text {friction }}+\dot{Q}_{\text {exhaust gas }}
$$

where $\dot{Q}_{\text {total }}$ is the total power provided by the fuel, $P_{i}$ is the useful mechanical power (or internal power) used for mobility and accessories, $\dot{Q}_{\text {coolant }}$ is the power adsorbed by the cooling system of the engine, $\dot{Q}_{\text {friction }}$ is the power dissipated by radiation and friction, $\dot{Q}_{\text {exhaust gas }}$ is the power expelled through the exhaust system.

There have been several studies to analyze and quantify the energy expelled in the exhaust gases and recover it for several applications $[6,9,10,24]$. While the power exploited for car mobility is:

$$
P_{i}=\text { Engine speed } \cdot \text { Torque }=(\mathrm{rpm}) \cdot(\mathrm{Nm})
$$

The total exhaust gas energy can be broken down into residual thermal energy, residual pressure energy, and residual kinetic energy, giving the following total energy equation:

$$
\dot{Q}_{\text {exhaust }}=\dot{Q}_{\text {kinetic }}+\dot{Q}_{\text {pressure }}+\dot{Q}_{\text {heat }}
$$


In the equation, $\dot{Q}_{\text {exhaust }}$ is the total flow of exhaust gas energy, $\mathrm{J} / \mathrm{s} ; \dot{Q}_{\text {kinetic }}$ is the flow of residual kinetic energy, J/s; $\dot{Q}_{\text {pressure }}$ is the flow of residual pressure energy, J/s; $\dot{Q}_{\text {heat }}$ is the flow of residual thermal energy, $\mathrm{J} / \mathrm{s}$.

The mass flow rate at the exhaust gas is equal to:

$$
\dot{m}_{\text {exhaust }}=\dot{m}_{\text {air }}+\dot{m}_{f u e l}
$$

In the equation above, $\dot{m}_{\text {exhaust }}, \dot{m}_{\text {air }}$ and $\dot{m}_{f u e l}$ are, respectively, the exhaust gas, air and fuel mass flow rates.

The specific heat capacity of the exhaust gas is a function of temperature; however, we can consider $c_{p}$ constant, by assuming the behavior of the exhaust gas as perfect. If the exhaust gas were assumed to be real gas, the use of a $c_{p}$ varying with temperature would give an error of $2-3 \%$ on the results of thermal power, which is acceptable, given the accuracy of the experimental measurements.

Therefore, the flow of residual thermal energy can be solved with the following equation:

$$
\dot{Q}_{\text {heat }}=\dot{m}_{\text {exhaust }} \cdot \int_{T_{0}}^{T_{\text {exhaust }}} c_{p} d T \sim \dot{m}_{\text {exhaust }} \cdot c_{p} \cdot \Delta T
$$

In the equation, $c_{p}$ is the specific heat capacity of exhaust gas [25], in $\mathrm{J} /(\mathrm{kg} \cdot \mathrm{K}) ; T_{e x}$ is the temperature of exhaust gas, in $\mathrm{K} ; T_{0}$ is the environment temperature, in $\mathrm{K}$.

The exhaust gas pressure energy can be calculated through the following equation [26]:

$$
\dot{Q}_{\text {pressure }}=\dot{m}_{\text {exhaust }} \cdot \frac{k}{k-1} \cdot R_{g} \cdot T_{e x} \cdot\left[1-{\frac{p_{0}}{p_{e x}}}^{\frac{k-1}{k}}\right]
$$

In the equation, $p_{e x}$ is the pressure of the exhaust gas; $p_{0}$ is the atmospheric pressure under standard conditions, $\mathrm{Pa} ; R_{\mathrm{g}}$ is the gas constant of the exhaust gas, $\mathrm{J} /(\mathrm{kg} \cdot \mathrm{K}) ; \kappa$ is the specific heat capacity.

The equation for the residual kinetic energy is:

$$
\dot{Q}_{\text {kinetic }}=\frac{1}{2} \cdot \rho_{\text {exhaust }} \cdot A \cdot v_{\text {exhaust }}{ }^{3}=\frac{1}{2} \cdot \dot{m}_{\text {exhaust }} \cdot v_{\text {exhaust }}{ }^{2}
$$

In the calculations of residual pressure energy and residual thermal energy, the standard atmospheric conditions are considered.

Any energy recovery system would need to operate in the harsh environment of the exhaust gas system. In order to design and maximize the efficiency of the harvester, it is fundamental to know the temperature, pressure and the speed of the exhaust gas, as well as information about the level of turbulence of the same gas. The purpose of the experimental session is to characterize the different parameters of the exhaust gas at different operating points of the engine, i.e., at different loads, torque, and rpm. Several works have been published related to the recovery of exhaust energy through thermal or pressure conversion $[6,9-11,13,27]$. However, kinetic energy can be potentially converted into useful electrical energy for powering IoT sensors for monitoring the gas properties such as concentration of polluting species, fuel not combusted or temperature. A special emphasis has been given to the calculation of the kinetic energy available in the exhaust gas with the goal in mind of converting it into electric power by means of piezoelectric conversion. A test of the conversion of kinetic energy of exhaust gas into electrical energy has been attempted using a flexible piezoelectric harvester.

\section{Materials and Methods}

\subsection{Tests at the Engine Bench}

The engine used for the measurements was an AUDI A4, year 2011, 2000cc, TDI, diesel engine of the VAG group developed by Audi; it is a four-cylinder in-line four-stroke compression ignition system, 
with four valves per cylinder, "turbocharged", and equipped with a common rail (CR) injection system. The engine delivers a maximum power of $105 \mathrm{~kW}(143 \mathrm{HP})$ at $4200 \mathrm{rpm}$ and a maximum torque of $320 \mathrm{Nm}$ between 1750 and $2500 \mathrm{rpm}$ (Figure 2).

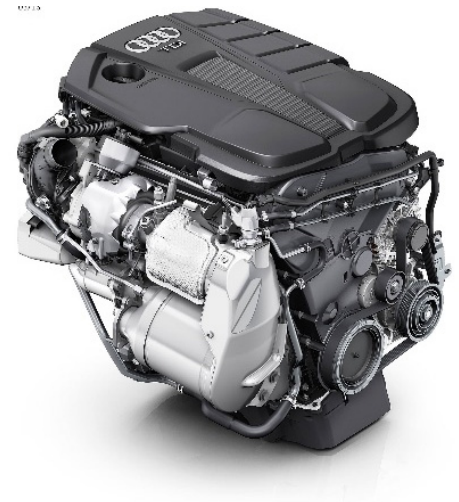

(a)

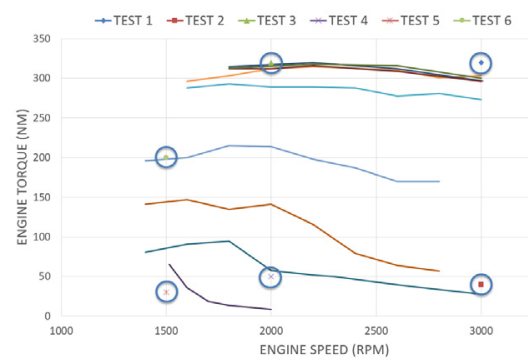

(c)

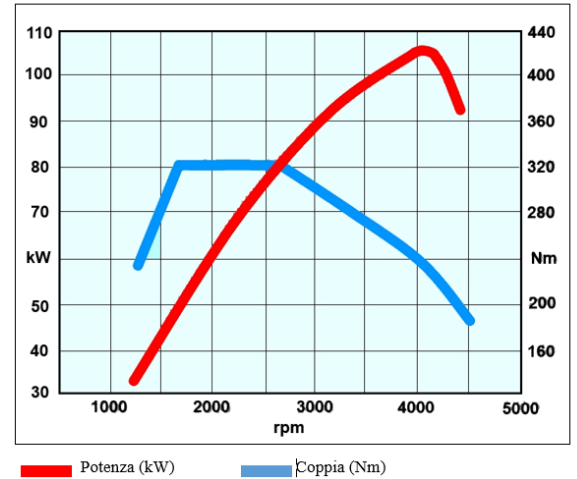

(b)

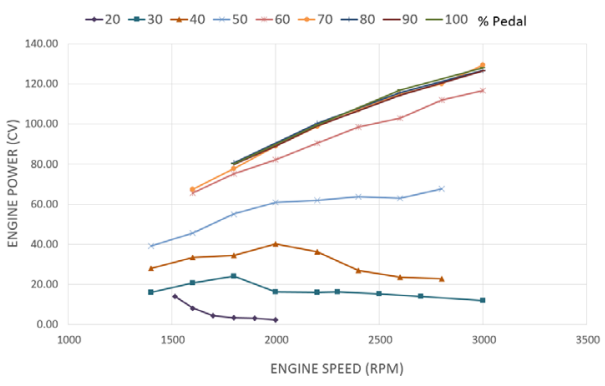

(d)

Figure 2. (a) Lab engine photo; (b) torque and power curves of the engine; (c) map of the engine and engine points explored, circled; (d) power curves of the engine, the legend shows the percentage of load (gas pedal).

In addition to the use of the common rail injection system and the piezoelectric injectors, which guarantee meticulous control of the quantity of fuel injected into the combustion chamber, thereby decreasing the quantity of unburned fuel expelled at the exhaust, other technologies, such as electric EGR valve (exhaust gas recirculation), an EGR cooling system, and a particulate filter equip the engine in order to lower polluting emissions.

These characteristics make the engine perfectly suited to the study thanks to the optimization of combustion, which limits the fluctuations of torque and power, and thanks to the use of the turbocharger, it allows for a range of air speeds in the intake and exhaust, interesting for the analysis of the energy harvesting system.

The power, torque and specific consumption curves for different percentages of pedal were obtained during several tests carried out in the "Internal Combustion Engines" laboratories of the University of Salento, to better characterize the engine and define the most interesting test points for the study.

The engine bench characterization and the implemented layout allowed for the experimental definition of the test engine points, checking of all the parameters of the control unit and the percentage of the pedal, and the ability to identify torque and power in urban, suburban and freeway use.

\subsection{Test Cycles}

The idea of defining the engine operating points was to define operating conditions characteristic of urban, suburban and freeway routes under particular driving conditions, which are listed in Table 1. 
Table 1. Engine points studied.

\begin{tabular}{ccccccc}
\hline & Point $\mathbf{1}$ & Point $\mathbf{2}$ & Point $\mathbf{3}$ & Point $\mathbf{4}$ & Point 5 & Point $\mathbf{6}$ \\
\hline RPM & 1500 & 1500 & 2000 & 2000 & 3000 & 3000 \\
Torque & 200 & 320 & 50 & 320 & 40 & 320 \\
Equivalent gear & 1 & 2 & 5 & 3 & 6 & 6 \\
\hline
\end{tabular}

The points described in Table 1 were inserted within the torque curves of the engine to establish the gas pedal percentages to be supplied to the engine in order to obtain the required torque and power as an output.

It should also be noted that points 3 and 5 are characterized by a low percentage of turbocharger operation, while points 2,4 and 6 represent the points of maximum torque that can be delivered by the engine at the given engine speed.

\subsection{Measurement Systems}

The average gas speed was measured with a pitot tube [28], which included also a thermocouple for measuring temperature, and data logger Testo 480 [29], with a sampling rate of 1 sample/sec.

The exhaust tube was drilled to host the pitot tube (approximately $6 \mathrm{~mm}$ in diameter), which was used to measure the total pressure and the dynamic pressure, from which the logger calculated the gas speed using Bernoulli's equation [30].

All parameters related to the engine were monitored and measured while driving on the road by using a commercial OBD II (on-board-diagnostics), which is a device that is connected to the electronic central unit (ECU) of the car. The OBD logger was inserted into the OBD port of the car, and the data collected were transferred via blue-tooth protocol to the mobile application.

\subsection{Exhaust Gas Positions}

As indicated below, the chosen measuring points were located along the exhaust line starting from downstream of the particulate filter up to the point of expulsion of the gases into the atmosphere.

The exhaust system studied is shown in Figure 3, with the 5 positions at which the gas was measured. Position 1, "Engine Exit", was directly downstream of the particulate filter; position 2, "Resonator" was in the empty cylinder approximately $600 \mathrm{~mm}$ downstream of position 1; position 3, "Between Resonator and Muffler" was approximately $300 \mathrm{~mm}$ downstream of the resonator; finally, positions 4 and 5 were the two exits of the muffler.

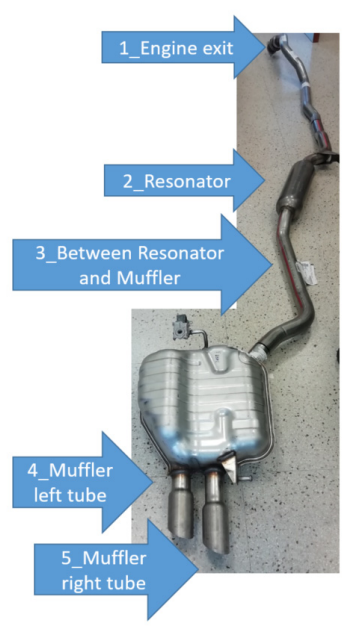

Figure 3. Exhaust system and characterized positions. Each muffler tube has a diameter of $60 \mathrm{~mm}$, and an area of $2800 \mathrm{~mm}^{2}$. 


\subsection{Piezoelectric Conversion}

According to the theory of flow around bluff bodies, introduced by T. von Karman [31], the Karman vortex street was created to improve the vibrational energy of the exhaust gas. The forces from shedding vortices make the flexible piezoelectric harvester (Aluminum Nitride-based) device vibrate periodically. The electromechanical energy conversion is then completed based on the direct piezoelectric effect, which is the process of formation of an electrical field within the material through the separation of charge due to applied strain. Figure 4 shows the process of the energy conversion from kinetic to electrical by the flexible piezoelectric harvester.

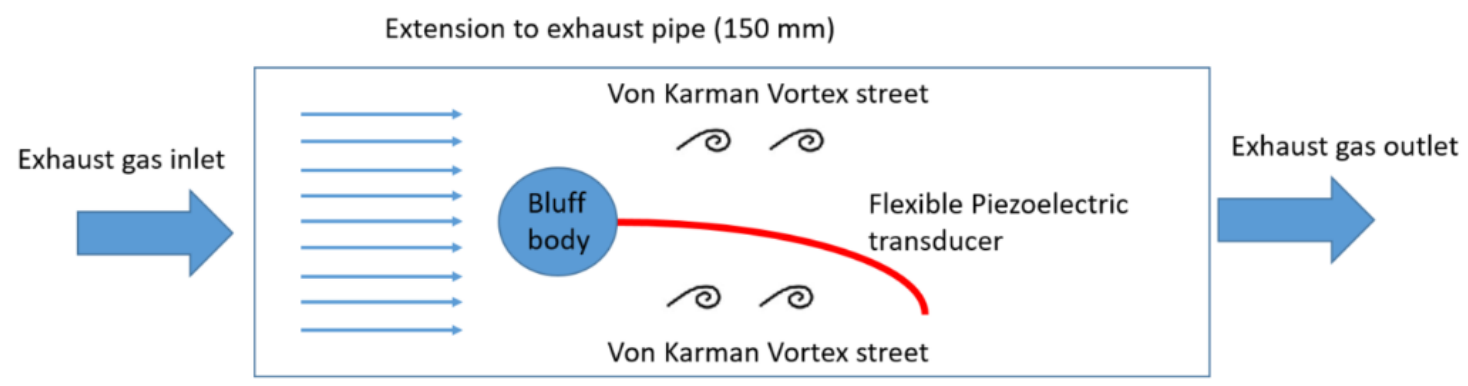

Figure 4. Schematic representation of the energy conversion from kinetic to electrical by the piezoelectric transducer.

The piezoelectric constitutive equations, also known as "coupled equations" are given below [32]:

$$
\begin{aligned}
& S=s^{E} T+d E \\
& D=d T+\varepsilon^{T} E
\end{aligned}
$$

where $S$ is the strain tensor, $s^{E}$ is the matrix of compliance coefficient, $T$ is the stress tensor, $\mathrm{d}$ is the matrix of the piezoelectric strain constant, $D$ is the tensor of elecric displacement, $\varepsilon^{T}$ is the permittivity.

\section{Results}

The data of mass flow of fuel and air were taken from the electronic central unit of the engine (ECU) relative to the different engine operating conditions, and are listed in Table 2.

Table 2. Measurements of gas flow at the exhaust relative to the different engine operating conditions.

\begin{tabular}{cccc}
\hline $\begin{array}{c}\text { Engine Operating Point } \\
\text { Speed_Torque } \\
\text { (rpm)_(Nm) }\end{array}$ & $\begin{array}{c}\text { Fuel Gas Flow } \\
\text { (mg/stroke) }\end{array}$ & $\begin{array}{c}\text { Fuel Mass Flow } \mathbf{1}^{-} \\
\text {(g/s) }\end{array}$ & $\begin{array}{c}\text { Total Mass Flow } \\
\text { (g/s) }\end{array}$ \\
\hline 1500_200 & 38.8 & 37 & 38.2 \\
1500_320 & 55.0 & 43 & 45.8 \\
2000_50 & 11.4 & 22 & 22 \\
2000_320 & 57.2 & 68 & 64.9 \\
3000_40 & 11.9 & 63 & 63 \\
3000_320 & 55.1 & 100 & 100.5 \\
\hline
\end{tabular}

${ }^{1}$ Fuel mass flow measured as mg/stroke, converted into $\mathrm{g} / \mathrm{s}$ by the formula $\mathrm{mg} / \mathrm{stroke}=4^{*} \mathrm{rpm} / 60(\mathrm{mg} / \mathrm{s})$.

\section{Detailed Results Relative to the Exhaust Gas for Each Exhaust Position}

The exhaust gas was characterized at different positions of the exhaust system, and gas pressure, gas speed and temperature were measured using the methods described in Materials and Methods. Detailed plots of the measured gas parameters are presented in Table A1, Table A2, Table A3 in Appendix at the end of the document. 
Results of the measurements are summarized in Figure 5.

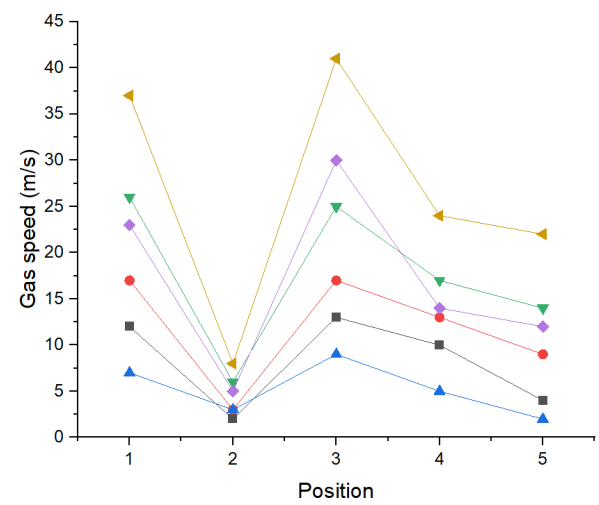

(a)

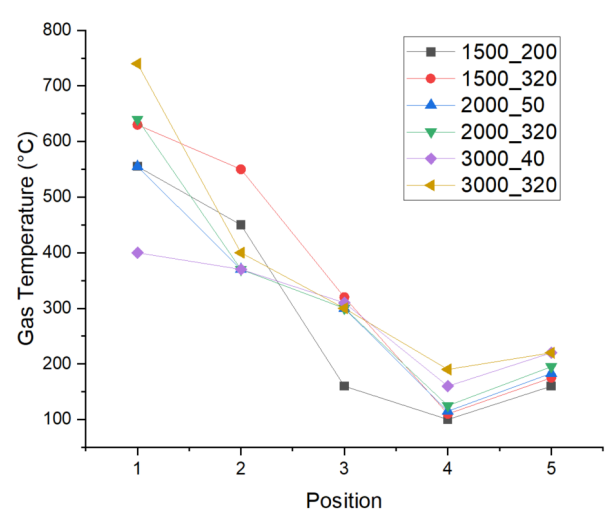

(c)

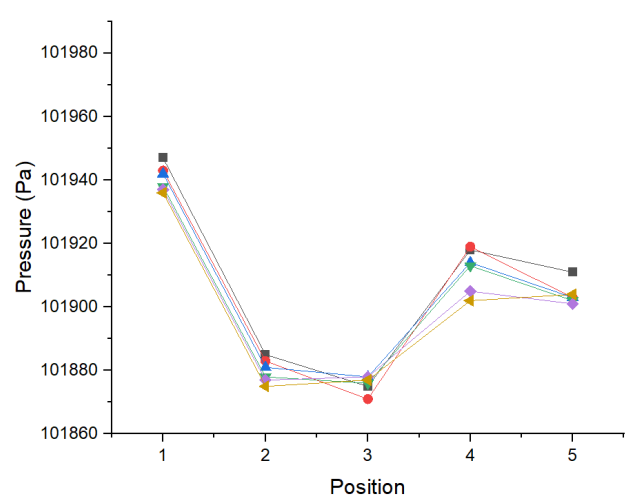

(b)

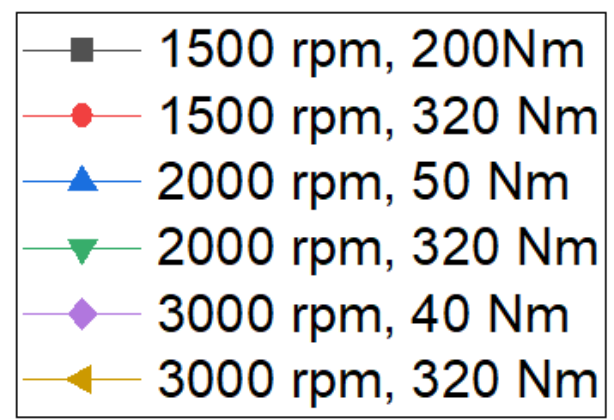

(d)

Figure 5. Summary of the exhaust gas properties at each exhaust line position. (a) Gas speed measured at each of the five positions of the exhaust system; (b) absolute gas static pressure at each of the five positions of the exhaust system; (c) gas temperature at each of the five positions of the gas exhaust system; (d) description of the operating engine points studied.

\section{Discussion}

Based on the data collected with the measurement of the fundamental gas properties, several calculations have been carried out using the equation presented in the introduction in order to calculate the power of the exhaust gas. A preliminary discussion on the measurement of the gas speed is presented first.

\subsection{Validation of Gas Speed Measured by Pitot Tube}

As described by Gonzales et al. [33], there is a high frequency component to the pressure waves of the exhaust gas, therefore the exhaust gas flow is not steady or constant. However, for the purpose of the present work, where the measurement of the gas speed has been performed with a sampling rate of 2 samples/s, we can consider the flow as quasi-static.

The average gas speed measured by the pitot tube has been compared with values of gas speed calculated by a mathematical model based on the measured mass flow of the gas speed at each engine point and the density and temperature of the gas, as shown in Table 3. The calculation of the average gas speed starting from the measured mass flow rate has been performed using Equation (8).

$$
\begin{aligned}
& \text { volume flow rate }=\frac{\text { mass flow rate }}{\text { density }} \\
& \text { gas velocity }=\frac{\text { volume flow rate }}{\text { area }}
\end{aligned}
$$


Table 3. Gas parameters at left muffler.

\begin{tabular}{|c|c|c|c|c|c|c|c|}
\hline $\begin{array}{l}\text { Engine Point } \\
\text { Rpm_Torque }\end{array}$ & $\begin{array}{l}\text { Total Mass } \\
\text { Flow } \\
\text { (g/s) }\end{array}$ & $\begin{array}{c}\text { Gas Density } \\
\left(\mathrm{kg} / \mathrm{m}^{3}\right)\end{array}$ & $\begin{array}{l}\text { Volume Flow } \\
\left(\mathrm{m}^{3} / \mathrm{s}\right) \times 10^{-3}\end{array}$ & $\begin{array}{c}\text { Cross Section } \\
\qquad\left(\mathrm{cm}^{2}\right)\end{array}$ & $\begin{array}{l}\text { Calculated } \\
\text { Speed } \\
(\mathrm{m} / \mathrm{s})\end{array}$ & $\begin{array}{c}\text { Measured } \\
\text { Speed } \\
(\mathrm{m} / \mathrm{s})\end{array}$ & $\begin{array}{c}\text { Error } \\
\%\end{array}$ \\
\hline 1500_200 & 38.2 & 0.81 & 47.2 & 56 & 8.4 & 9 & 6.4 \\
\hline 1500320 & 45.8 & 0.79 & 58.0 & 56 & 10.4 & 11 & 5.9 \\
\hline 2000_50 & 22 & 0.77 & 28.6 & 56 & 5.1 & 5 & 2.0 \\
\hline 2000_320 & 69.4 & 0.75 & 92.5 & 56 & 16.5 & 16 & 3.3 \\
\hline $3000 \quad 40$ & 63 & 0.72 & 87.5 & 56 & 15.6 & 15 & 4.2 \\
\hline 3000_320 & 100.5 & 0.72 & 139.6 & 56 & 24.9 & 23 & 8.4 \\
\hline
\end{tabular}

As described in previous work [34,35], the main component of the gas exhaust as it is in the air is $\mathrm{N}_{2}$. When considering the gas properties, neglecting the combustion products the error is typically not higher than $2 \%$, therefore we have used air density when needed for the gas exhaust.

Given the relatively small discrepancy between measured and calculated values, the measured values of the gas speed can be considered reliable, therefore they have been used for the calculation of the kinetic energy in the following sections.

\subsection{Estimation of Power at the Engine Exhaust for the Bench Engine}

Three forms of energy at the exhaust were evaluated, and the power was calculated using Equations (5)-(7) for thermal, pressure and kinetic power, respectively. The results showed that thermal power was by far the most dominant form of power present in the exhaust gas, followed by pressure power, and finally kinetic power was the smallest fraction.

Figure $6 \mathrm{a}-\mathrm{c}$ give a graphic summary of the power results. Figure $6 \mathrm{~d}$ shows the trend of the different forms of power with the value of the torque fixed at $320 \mathrm{~N}^{*} \mathrm{~m}$, while the engine speed (RPM) variable between $1500 \mathrm{rpm}$ and $3000 \mathrm{rpm}$, which is the most common range of engine speeds experienced in real driving conditions. Figure $6 \mathrm{~d}$ represents the values on the $Y$-axis with a logarithmic scale, showing the kinetic power in the order of $\mathrm{W}$, which was a small fraction of the exhaust energy available in other forms (thermal and pressure).

It is noteworthy that in position 2 (resonator), the pressure was approximately the same as the pressure measured in position 3 (between resonator and muffler). However, the gas speed, and consequently the kinetic energy associated with the gas, was significantly higher in position 3 compared to position 2. The reason for this behavior is currently unclear. The exhaust system is a complex fluid dynamic environment, in which several factors such as cross-section variation, pressure wave propagation and reflection and heat exchange, contribute to complex effects on the gas speed. For example, pressure wave propagation leads to maxima and minima which could be further emphasized in positions closer to the resonator. Further studies would be needed to clarify these aspects. 


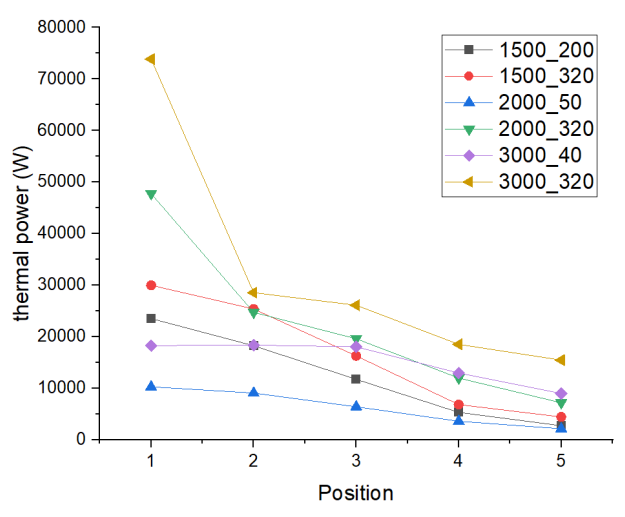

(a)

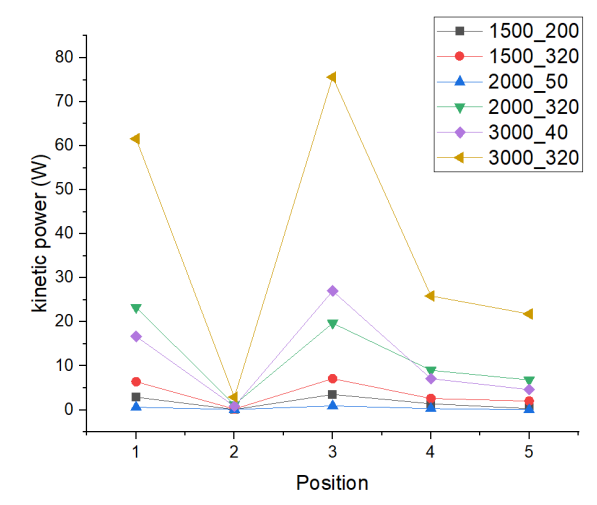

(c)

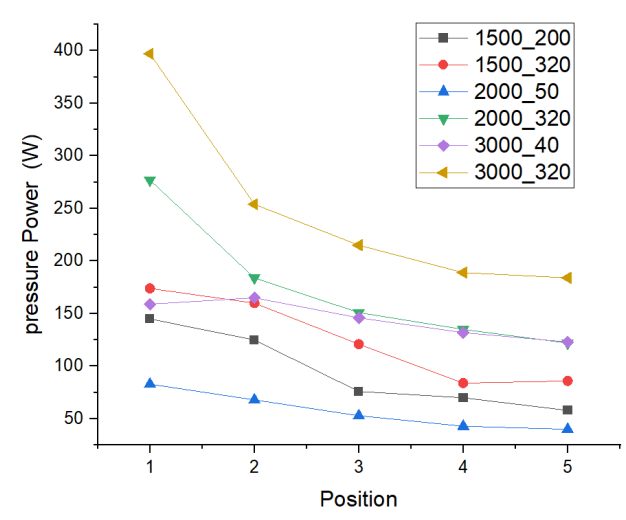

(b)

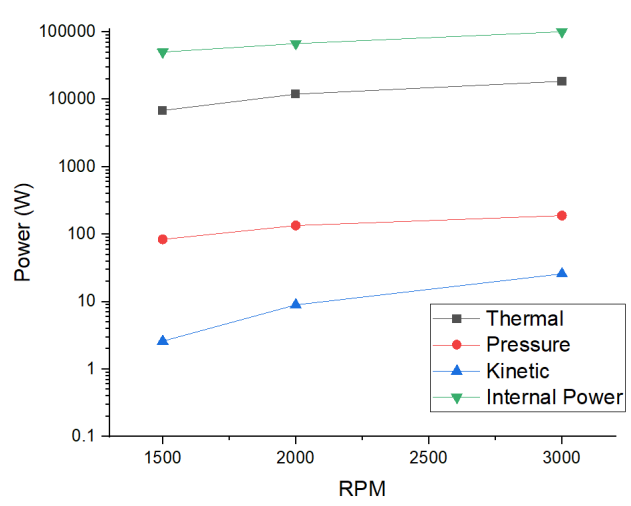

(d)

Figure 6. Summary of power calculations at different engine points and at each of the five exhaust locations: (a) thermal power; (b) pressure power and (c) kinetic power, (d) thermal, kinetic, pressure and internal power.

\subsection{Piezoelectric Conversion from the Exhaust Pipe under Real Driving Conditions}

Real driving emission conditions were evaluated by carrying out measurements of the exhaust gas while driving a car on the road. The car tested was a Fiat Freemont 2000cc TDI, therefore equipped with an engine very similar to the one tested in the lab. In addition to measuring pressure, temperature and gas speed of the exhaust gas, a first test on the piezoelectric conversion was performed in order to evaluate the efficiency of the energy conversion. A flexible piezoelectric transducer fabricated according to the process described by Guido et al. [19,34] was held inside the exhaust pipe, and the electrical signal generated by the piezoelectric transducer was recorded and shown in the figure below.

Figure 7 shows the parameters of the engine and the exhaust gas measured simultaneously during the real driving conditions road test. The temperature of the exhaust gas at the muffler grew rapidly over $100{ }^{\circ} \mathrm{C}$, therefore the choice of the material of any harvester needs to consider this constraint.

The harvester used in this work was made of piezoelectric aluminum nitride on a flexible substrate of polyimide (commercial Kapton). Theoretical models showed that harvester efficiency could experience a drop with temperature due to thermal stresses [35]. Noteworthy, no creeps in the aluminum nitride piezoelectric layer were observed with temperature, suggesting the harvesting device could withstand the temperature range measured. The gas speed was generally below $10 \mathrm{~m} / \mathrm{s}$, with a few spikes over $15-20 \mathrm{~m} / \mathrm{s}$. 


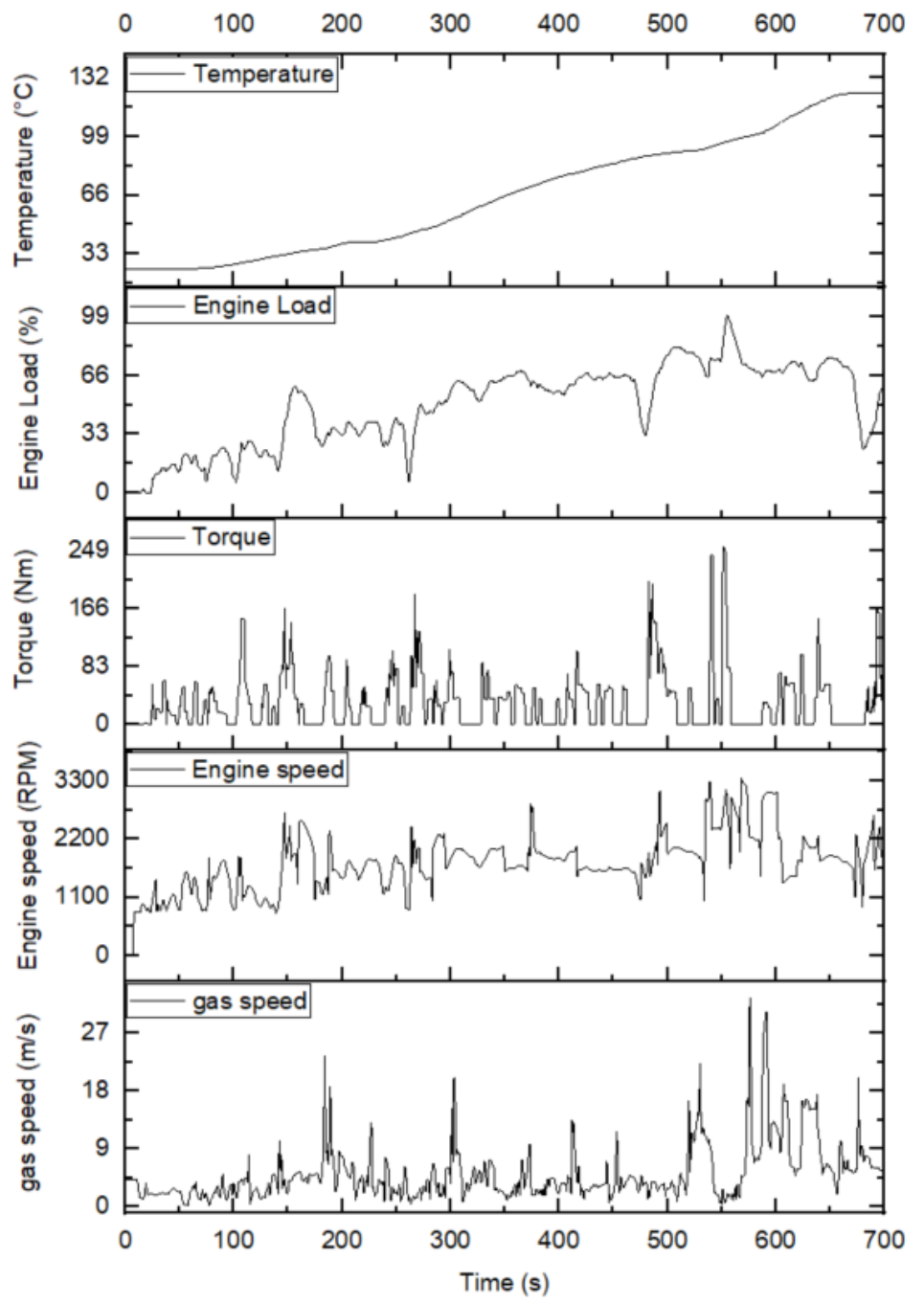

Figure 7. Recorded real driving conditions parameters.

Figure 8a shows the bluff body and holder of the piezoelectric harvester, made of a polyimide substrate and 1 micron thick layer of piezoelectric AlN, responsible for the electro-mechanical conversion during the vortex-induced vibration. No visible buildup of carbon on the harvester, potentially changing its mechanical response, was observed, even after repeated tests. The deposition of carbon cannot be excluded, and further study will be conducted to determine its potential effect. Figure $8 \mathrm{~d}$ shows the retrofit system including the harvester and the measurement setup of the exhaust gas. Figure $8 \mathrm{c}$ shows the voltage generated during the car drive of approximately $10 \mathrm{~min}$ in a mix of urban and extra-urban settings. The power calculated based on the voltage measured at the piezoelectric device using a $1 \mathrm{Mohm}$ probe is reported in Figure $8 \mathrm{~d}$. There was a delay between the spikes of RPM, torque and engine load, and the spikes of voltage generated that were not synchronized with the peaks of the engine parameters. Considering that the harvester is based on a vortex-induced vibration mechanism, it is possible that the piezoelectric conversion could be more efficient during the transitions between operating conditions of the engine than in fixed regime conditions. These topics will be treated in following studies in order to optimize the design of the harvester. 


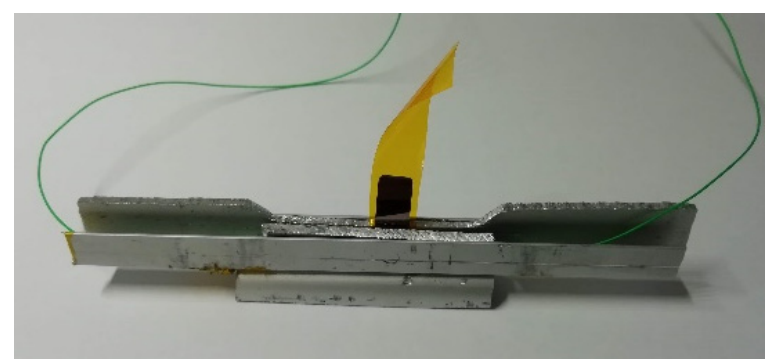

(a)

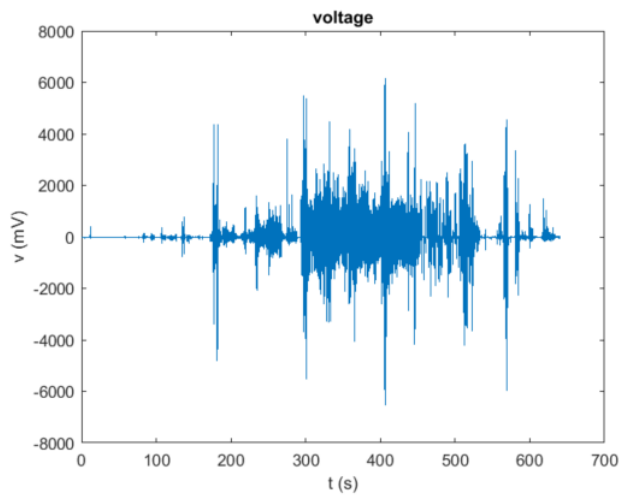

(c)

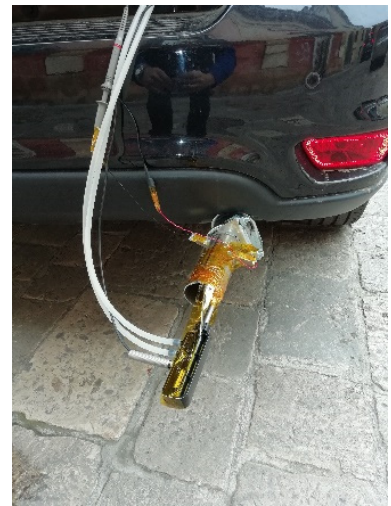

(b)

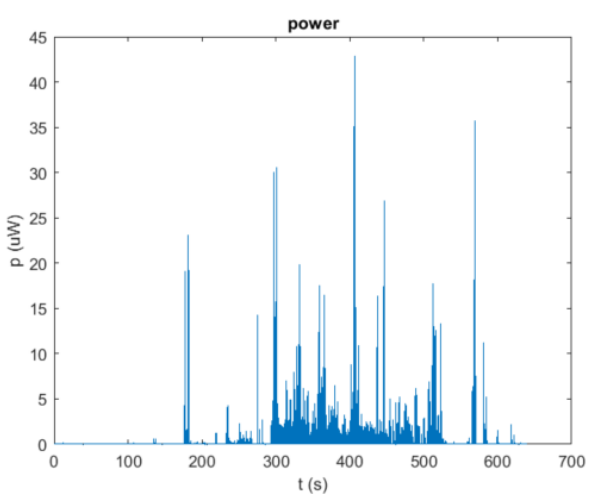

(d)

Figure 8. Summary of the real driving condition measurements: (a) piezoelectric converter mounted on the aluminum bluff body; (b) extender of the exhaust pipe at the muffler for mounting the piezoelectric harvester in retrofit; (c) voltage of electrical signal generated by the piezoelectric flexible transducer; (d) instant power calculated from the voltage.

Table 4 summarizes the electrical voltage, power and energy generated by the piezoelectric harvester during the $10 \mathrm{~min}$ ride on the road. Although the harvester generated a few peaks of power in the order of $\mu \mathrm{W}$, the average power was in the order of $\mathrm{nW}$. The simultaneous use of several harvesters working in parallel could be pursued but, in order to enhance the efficiency of the whole system, the set of harvesters needs to work in phase. Recently, the optimization of energy harvesters networks through Artificial Intelligence have shown a valuable strategy to follow [36].

Table 4. Electrical energy, voltage, power.

\begin{tabular}{ccccc}
\hline Voltage Average & Voltage Max & Energy & Power Average & Power Max \\
\hline $74 \mathrm{mV}$ & $6.5 \mathrm{~V}$ & $21 \mu \mathrm{J}$ & $33 \mathrm{nW}$ & $42 \mu \mathrm{W}$ \\
\hline
\end{tabular}

\subsection{Efficiency of Piezoelectric Harvester}

The efficiency of the piezoelectric harvester was evaluated at several gas speeds. The efficiency curve was constructed by dividing the electrical power output by the available fluid power (kinetic power) available in the cross-sectional area in which the harvester operated, according to the following equation:

$$
\eta=P /\left(\frac{1}{2} \cdot \rho \cdot A \cdot v^{3}\right)
$$


where $\eta$ is the efficiency, $P$ is the electrical power outout, $\rho$ is the air density, $A$ is the cross sectional area presented to the incoming stream and $v$ is the air velocity [37]. Figure 9 shows the trend of the efficiency of conversion of the piezoelectric harvester.

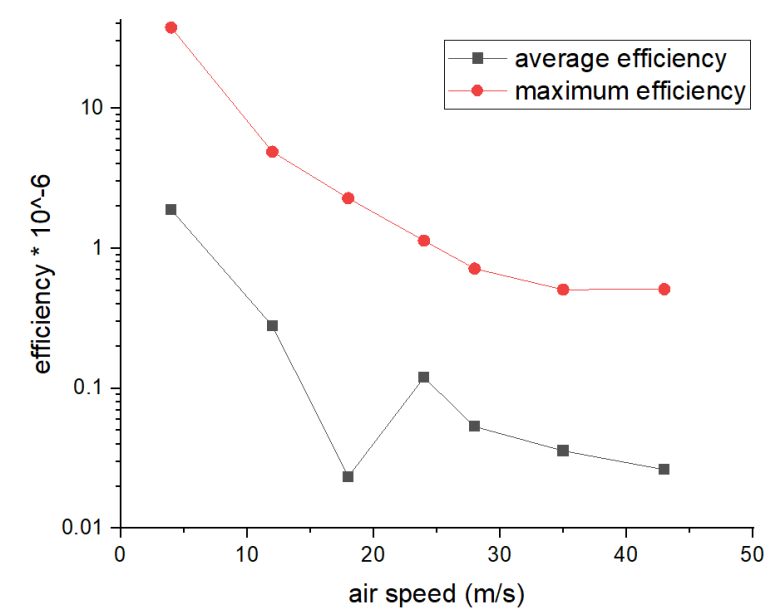

Figure 9. Efficiency (logarithmic scale) of AlN-based piezoelectric harvester.

It was noticeable that there was a decreasing trend of efficiency with increasing gas speed, probably due to a couple of factors: von Karman vortex excitation losing efficacy on the piezoelectric component, and possible generation of opposite charge in different parts of the piezoelectric component due to vibrational modes different from mode I. Further studies are needed to explain this trend.

\section{Conclusions}

The gas at the exhaust of an internal combustion engine carries power that can be classified in three portions: thermal, pressure and kinetic. The thermal power is most dominant, with values in the order of $\mathrm{kW}$, while the pressure and the kinetic are of the order of watts at the exhaust muffler.

Temperature rapidly exceeds $120^{\circ} \mathrm{C}$ in most of the points of the exhaust system at several engine points. Therefore, the use of piezoelectric harvesters has to be restricted to materials whose piezoelectric properties can withstand those temperatures. The piezoelectric conversion, using high temperature-resistant transducers (AlN on polyimide), has been demonstrated to be a good candidate to be used as an energy harvester in a harsh environment in the exhaust system. However, further studies are needed to study the influence of temperature (in the range of the exhaust gas temperatures), in order to quantify its effect on the performance of the device as a whole.

Author Contributions: Conceptualization, methodology, validation, formal analysis, investigation, data curation, writing-original draft preparation, F.M., I.M., F.G. and A.C.; writing-review and editing, F.R.; supervision, M.D.V. and A.P.C. All authors have read and agreed to the published version of the manuscript.

Funding: HORIZON 2020" PON I\&C 201- "Recupero di Energia Meccanica da fluidi per internet delle cose e sensori remoti (REM)" n. F/050111/01-03/X32.

Conflicts of Interest: The authors declare no conflict of interest.

\section{Appendix A}

Results of measurement of temperature, pressure and gas speed of the exhaust gas are summarized below in Table A1, Table A2, Table A3. 
Table A1. Results summary: gas speed.

\begin{tabular}{|c|c|c|c|c|c|c|}
\hline \multicolumn{2}{|c|}{$\begin{array}{c}\text { Engine Regime Rpm Torque } \\
\text { Position \# }\end{array}$} & \multirow{2}{*}{$\begin{array}{c}\text { Engine Exit } \\
\mathbf{1} \\
12 \mathrm{~m} / \mathrm{s}\end{array}$} & \multirow{2}{*}{$\begin{array}{c}\text { Resonator } \\
\mathbf{2} \\
2 \mathrm{~m} / \mathrm{s}\end{array}$} & \multirow{2}{*}{$\begin{array}{c}\text { Between } \\
\text { Resonator/Muffler } \\
\mathbf{3} \\
13 \mathrm{~m} / \mathrm{s}\end{array}$} & \multirow{2}{*}{$\begin{array}{c}\text { Muffler } \\
\text { Right Tube } \\
4 \\
4 \mathrm{~m} / \mathrm{s}\end{array}$} & \multirow{2}{*}{$\begin{array}{c}\text { Muffler Left Tube } \\
\qquad \mathbf{5} \\
9 \mathrm{~m} / \mathrm{s}\end{array}$} \\
\hline $1500 \mathrm{rpm}$ & $30 \mathrm{Nm}$ & & & & & \\
\hline $1500 \mathrm{rpm}$ & $320 \mathrm{Nm}$ & $17 \mathrm{~m} / \mathrm{s}$ & $3 \mathrm{~m} / \mathrm{s}$ & $17 \mathrm{~m} / \mathrm{s}$ & $9 \mathrm{~m} / \mathrm{s}$ & $11 \mathrm{~m} / \mathrm{s}$ \\
\hline $2000 \mathrm{rpm}$ & $50 \mathrm{Nm}$ & $7 \mathrm{~m} / \mathrm{s}$ & $3 \mathrm{~m} / \mathrm{s}$ & $9 \mathrm{~m} / \mathrm{s}$ & $2 \mathrm{~m} / \mathrm{s}$ & $5 \mathrm{~m} / \mathrm{s}$ \\
\hline $2000 \mathrm{rpm}$ & $320 \mathrm{Nm}$ & $26 \mathrm{~m} / \mathrm{s}$ & $6 \mathrm{~m} / \mathrm{s}$ & $25 \mathrm{~m} / \mathrm{s}$ & $14 \mathrm{~m} / \mathrm{s}$ & $16 \mathrm{~m} / \mathrm{s}$ \\
\hline $3000 \mathrm{rpm}$ & $40 \mathrm{Nm}$ & $23 \mathrm{~m} / \mathrm{s}$ & $5 \mathrm{~m} / \mathrm{s}$ & $30 \mathrm{~m} / \mathrm{s}$ & $12 \mathrm{~m} / \mathrm{s}$ & $15 \mathrm{~m} / \mathrm{s}$ \\
\hline $3000 \mathrm{rpm}$ & $320 \mathrm{Nm}$ & $37 \mathrm{~m} / \mathrm{s}$ & $8 \mathrm{~m} / \mathrm{s}$ & $41 \mathrm{~m} / \mathrm{s}$ & $22 \mathrm{~m} / \mathrm{s}$ & $23 \mathrm{~m} / \mathrm{s}$ \\
\hline
\end{tabular}

Table resembling Table A2 of the article by Nontharkan [26].

Table A2. Results summary: temperature.

\begin{tabular}{|c|c|c|c|c|c|c|}
\hline \multicolumn{2}{|c|}{$\begin{array}{c}\text { Engine Regime Rpm Torque } \\
\text { Position \# }\end{array}$} & \multirow{2}{*}{$\begin{array}{c}\text { Engine Exit } \\
\qquad \begin{array}{c}\mathbf{1} \\
485^{\circ} \mathrm{C}\end{array}\end{array}$} & \multirow{2}{*}{$\begin{array}{c}\text { Resonator } \\
\mathbf{2} \\
450{ }^{\circ} \mathrm{C}\end{array}$} & \multirow{2}{*}{$\begin{array}{c}\text { Between } \\
\begin{array}{c}\text { Resonator/Muffler } \\
3\end{array} \\
280^{\circ} \mathrm{C}\end{array}$} & \multirow{2}{*}{$\begin{array}{c}\text { Muffler } \\
\text { Right Tube } \\
4\end{array}$} & \multirow{2}{*}{$\begin{array}{l}\text { Muffler Left Tube } \\
\frac{5}{165^{\circ} \mathrm{C}}\end{array}$} \\
\hline $1500 \mathrm{rpm}$ & $30 \mathrm{Nm}$ & & & & & \\
\hline $1500 \mathrm{rpm}$ & $320 \mathrm{Nm}$ & $630^{\circ} \mathrm{C}$ & $550{ }^{\circ} \mathrm{C}$ & $320^{\circ} \mathrm{C}$ & $110^{\circ} \mathrm{C}$ & $175^{\circ} \mathrm{C}$ \\
\hline $2000 \mathrm{rpm}$ & $50 \mathrm{Nm}$ & $340^{\circ} \mathrm{C}$ & $370^{\circ} \mathrm{C}$ & $300^{\circ} \mathrm{C}$ & $115^{\circ} \mathrm{C}$ & $183^{\circ} \mathrm{C}$ \\
\hline $2000 \mathrm{rpm}$ & $320 \mathrm{Nm}$ & $640^{\circ} \mathrm{C}$ & $380^{\circ} \mathrm{C}$ & $300^{\circ} \mathrm{C}$ & $125^{\circ} \mathrm{C}$ & $195^{\circ} \mathrm{C}$ \\
\hline $3000 \mathrm{rpm}$ & $40 \mathrm{Nm}$ & $645^{\circ} \mathrm{C}$ & $370^{\circ} \mathrm{C}$ & $310^{\circ} \mathrm{C}$ & $160^{\circ} \mathrm{C}$ & $220^{\circ} \mathrm{C}$ \\
\hline $3000 \mathrm{rpm}$ & $320 \mathrm{Nm}$ & $740^{\circ} \mathrm{C}$ & $400{ }^{\circ} \mathrm{C}$ & $300^{\circ} \mathrm{C}$ & $190^{\circ} \mathrm{C}$ & $220^{\circ} \mathrm{C}$ \\
\hline
\end{tabular}

Table A3. Results Summary: pressure (kPa).

\begin{tabular}{|c|c|c|c|c|c|c|}
\hline \multicolumn{2}{|c|}{$\begin{array}{c}\text { Engine Regime Rpm Torque } \\
\text { Position \# }\end{array}$} & \multirow{2}{*}{$\begin{array}{c}\text { Engine Exit } \\
\mathbf{1} \\
164\end{array}$} & \multirow{2}{*}{$\begin{array}{c}\text { Resonator } \\
\mathbf{2} \\
167\end{array}$} & \multirow{2}{*}{$\begin{array}{c}\text { Between } \\
\text { Resonator/Muffler } \\
\mathbf{3} \\
162\end{array}$} & \multirow{2}{*}{$\begin{array}{c}\begin{array}{c}\text { Muffler } \\
\text { Right Tube } \\
\mathbf{4}\end{array} \\
101\end{array}$} & \multirow{2}{*}{$\begin{array}{c}\text { Muffler Left Tube } \\
\mathbf{5} \\
101\end{array}$} \\
\hline $1500 \mathrm{rpm}$ & $30 \mathrm{Nm}$ & & & & & \\
\hline $1500 \mathrm{rpm}$ & $320 \mathrm{Nm}$ & 182 & 200 & 190 & 101 & 101 \\
\hline $2000 \mathrm{rpm}$ & $50 \mathrm{Nm}$ & 116 & 120 & 117 & 101 & 101 \\
\hline $2000 \mathrm{rpm}$ & $320 \mathrm{Nm}$ & 225 & 225 & 225 & 101 & 101 \\
\hline $3000 \mathrm{rpm}$ & $40 \mathrm{Nm}$ & 137 & 133 & 135 & 101 & 101 \\
\hline $3000 \mathrm{rpm}$ & $320 \mathrm{Nm}$ & 225 & 225 & 225 & 101 & 101 \\
\hline
\end{tabular}

\section{References}

1. Hooftman, N.; Messagie, M.; Van Mierlo, J.; Coosemans, T. A review of the European passenger car regulations-Real driving emissions vs. local air quality. Renew. Sustain. Energy Rev. 2018, 86, 1-21. [CrossRef]

2. Williams, M.; Minjares, R. A technical summary of Euro 6/VI vehicle emission standards. The International Council on Clean Transportation. Available online: http://www.indiaenvironmentportal.org.in/files/file/ ICCT_Euro6-VI_briefing.pdf (accessed on 2 May 2020).

3. Fontaras, G.; Ciuffo, B.; Zacharof, N.; Tsiakmakis, S.; Marotta, A.; Pavlovic, J.; Anagnostopoulos, K. The difference between reported and real-world CO2 emissions: How much improvement can be expected by WLTP introduction? Transp. Res. Procedia 2017, 25, 3933-3943. [CrossRef]

4. Varella, R.; Giechaskiel, B.; Sousa, L.; Duarte, G.; Weiss, M.; Bonnel, P.; Hummel, R.; Steininger, N.; Djoric, V.; Jovic, J.; et al. Comparison of Portable Emissions Measurement Systems (PEMS) with Laboratory Grade Equipment. Appl. Sci. 2018, 8, 1633. [CrossRef]

5. Djoric, V.; Jovic, J.; Vukanovic, S. Collection and assessment of instantaneous vehicle emissions on street network. In Proceedings of the Transport Research Arena (TRA) 5th Conference: Transport Solutions from Research to Deployment European Commission, Paris, Italy, 14-17 April 2014.

6. Hossain, S.N.; Bari, S. Waste heat recovery from exhaust of a diesel generator set using organic fluids. Procedia Eng. 2014, 90, 439-444. [CrossRef]

7. Hossain, S.N.; Bari, S. Additional power generation from waste energy of diesel engine using parallel flow shell and tube heat exchanger. J. Eng. Gas Turbines Power 2014, 136, 100-104. [CrossRef] 
8. Fern, P.; Armas, O.; Gil, A. Developing Computational Fluid Dynamics (CFD) Models to Evaluate Available Energy in Exhaust Systems of Diesel Light-Duty Vehicles. Appl. Sci. 2017, 7, 590. [CrossRef]

9. Jadhao, J.S.; Thombare, D.G.; Student, P.G.; Sangali, D. Review on Exhaust Gas Heat Recovery for IC engine. Int. J. Eng. Innov. Technol. (IJEIT) Vol. 2013, 2, 93-100.

10. Orido, G.; Ngunjiri, P.G.; Njue, D.M. Exhaust Gases Energy Recovered from Internal Combustion Engine for Useful Applications. IOSR J. Mech. Civ. Eng. 2017, 14, 01-07. [CrossRef]

11. Guduru, K.K. Power Generation by using Kinetic Energy of Exhaust Gases from an Internal Combustion Engine. Int. J. Res. Comput. Technol. 2019, 7, 1-5.

12. Alshammari, M.; Alshammari, F.; Pesyridis, A. Electric boosting and energy recovery systems for engine downsizing. Energies 2019, 12, 4636. [CrossRef]

13. Ismail, B.I. Automotive exhaust gas waste-heat recovery for green electrical power generation using Thermoelectric technology. Recent Pat. Electr. Electron. Eng. 2012, 5, 185-197. [CrossRef]

14. Weiss, M.; Bonnel, P.; Hummel, R.; Steininger, N. A Complementary Emissions Test for Light-Duty Vehicles: Assessing the Technical Feasibility of Candidate Procedures; Conclusions of the Real-Driving Emissions-Light-Duty Vehicles (RDE-LDV) working group; Publications Office of the European Union: Brussels, Belgium, 2013. [CrossRef]

15. Valencia, G.; Fontalvo, A.; Cárdenas, Y.; Duarte, J.; Isaza, C. Energy and exergy analysis of different exhaust waste heat recovery systems for natural gas engine based on ORC. Energies 2019, 12, 2378. [CrossRef]

16. Fu, J.; Liu, J.; Yang, Y.; Yang, H. A Study on the Prospect of Engine Exhaust Gas Energy Recovery. In Proceedings of the 2011 International Conference on Electric Information and Control Engineering, Wuhan, China, 15-17 April 2011; IEEE: Miami, FL, USA, 2011; pp. 1960-1963. [CrossRef]

17. Gomes, J.B.A.; Rodrigues, J.J.P.C.; Rabêlo, R.A.L.; Kumar, N.; Kozlov, S. IoT-enabled gas sensors: Technologies, applications, and opportunities. J. Sens. Actuator Netw. 2019, 8, 57. [CrossRef]

18. Todaro, M.T.; Guido, F.; Mastronardi, V.; Desmaele, D.; Epifani, G.; Algieri, L.; De Vittorio, M. Piezoelectric MEMS vibrational energy harvesters: Advances and outlook. Microelectron. Eng. 2017, 183-184, $23-36$. [CrossRef]

19. Guido, F.; Qualtieri, A.; Algieri, L.; Lemma, E.D.; De Vittorio, M.; Todaro, M.T. AlN-based flexible piezoelectric skin for energy harvesting from human motion. Microelectron. Eng. 2016, 159, 174-178. [CrossRef]

20. Lee, Y.J.; Qi, Y.; Zhou, G.; Lua, K.B. Vortex-induced vibration wind energy harvesting by piezoelectric MEMS device in formation. Sci. Rep. 2019, 9, 1-11. [CrossRef] [PubMed]

21. Boulahlib, M.S.; Boukebbab, S.; Gaci, F.; Kholai, O. Experimental study of energy balance for air-cooled di diesel engines operating in hot climates. SAE Tech. Pap. 2009. [CrossRef]

22. Taymaz, I. An experimental study of energy balance in low heat rejection diesel engine. Energy 2006, 31, 364-371. [CrossRef]

23. Fairbanks, J.W. The 60 Percent Efficient Diesel Engine; Probable, Possible, or Just A Fantasy? In Proceedings of the 2005 Diesel Engine Emissions Reduction (DEER) Conference Presentations, US Department of Energy Chicago, Chicago, IL, USA, 24 August 2005.

24. Gopal, K.N.; Subbarao, R.; Pandiyarajan, V.; Velraj, R. Thermodynamic analysis of a diesel engine integrated with a PCM based energy storage system. Int. J. Thermodyn. 2010, 13, 15-21. [CrossRef]

25. Kyle, B.G. Chemical and Process Thermodynamics; Englewood Cliffs/Prentice Hall: Upper Saddle River, NJ, USA, 1984.

26. Dubois, E.; Mercier, A. Design and Optimization of an Integrated Turbo-Generator and Thermoelectric Generator for Vehicle Exhaust Electrical Energy Recovery. Energy Recover. 2009, 1-329. [CrossRef]

27. Koshy, A.P.; Jose, B.K.; Johnson, J.E.; Krishnan, K.N. Exhaust Gas Waste Heat Recovery and Utilization System in ICEngine. Int. J. Innov. Res. Sci. Technol. 2015, 1, 392-400.

28. Testo. Tubo di Pitot Diritto $360 \mathrm{~mm}$. Available online: https://www.testo.com/it-IT/tubo-di-pitot-diritto-360mm/p/0635-2043 (accessed on 1 April 2020).

29. Testo 480 Data Logger. Available online: https://www.testo.com/en-US/testo-480/p/0563-4800 (accessed on 1 April 2020).

30. Saleh, J.M. Fluid Flow Handbook; McGraw-Hill Professional: New York, NY, USA, 2002.

31. Von Karman, T. Aerodynamics; McGraw-Hill: New York, NY, USA, 1963; ISBN 978-0-486-43485-8.

32. Townley, A. Vibrational Energy Harvesting Using Mems Piezoelectric Generators. Available online: https: //sunfest.seas.upenn.edu/wp-content/uploads/2018/07/TownleyAndrew09.pdf (accessed on 7 June 2020). 
33. Fonseca González, N.; Casanova Kindelán, J.; López Martínez, J.M. Methodology for instantaneous average exhaust gas mass flow rate measurement. Flow Meas. Instrum. 2016, 49, 52-62. [CrossRef]

34. Petroni, S.; Rizzi, F.; Guido, F.; Cannavale, A.; Donateo, T.; Ingrosso, F.; Mastronardi, V.M.; Cingolani, R.; De Vittorio, M. Flexible AlN flags for efficient wind energy harvesting at ultralow cut-in wind speed. RSC Adv. 2015, 5, 14047-14052. [CrossRef]

35. Arroyo, E.; Jia, Y.; Du, S.; Chen, S.T.; Seshia, A.A. Experimental and theoretical study of a piezoelectric vibration energy harvester under high temperature. J. Microelectromechanical Syst. 2017, 26, 1216-1225. [CrossRef]

36. Nabavi, S.; Zhang, L. Design and Optimization of a Low-Resonant-Frequency Piezoelectric MEMS Energy Harvester Based on Artificial Intelligence. Proceedings 2018, 2, 930. [CrossRef]

37. Weinstein, L.A.; Cacan, M.R.; So, P.M.; Wright, P.K. Vortex shedding induced energy harvesting from piezoelectric materials in heating, ventilation and air conditioning flows. Smart Mater. Struct. 2012, 21. [CrossRef]

(C) 2020 by the authors. Licensee MDPI, Basel, Switzerland. This article is an open access article distributed under the terms and conditions of the Creative Commons Attribution (CC BY) license (http://creativecommons.org/licenses/by/4.0/). 